\title{
SOFT-HANDLING GRIPPER DRIVEN BY PIEZOCERAMIC BIMORPH STRIPS
}

\author{
S. Chonan ${ }^{1}$ Z.W. Jiang ${ }^{1}$ and M. Koseki ${ }^{2}$ \\ ${ }^{1}$ Department of Mechatronics and Precision Engineering \\ Tohoku University, Sendai, 980-77, Japan \\ ${ }^{2}$ System Engineering Department, Hino Works \\ Toshiba Corporation, Hino 191, Japan
}

This paper is a study of a minute force control of a two-fingered miniature gripper driven by piezoelectric bimorph cells. The system is composed of two flexible cantilevers and a compact force sensor attached to the tip on one finger. Control action is applied by a co-located set of piezoelectric bimorph strips placed at the base of each finger. The mathematical model of the electro-mechanical system is developed and applied to the study of a control problem where the gripper is commanded to grasp its object with a time-constant force $0.01 \mathrm{~N}$. The PID control algorithm is introduced and the dynamics and control behaviour of the system are investigated both theoretically and experimentally. The obtained results can be summarized as follows.

(1) The present artificial finger system works well as a miniature gripper. It can control the fingertip force on the order of $0.01 \mathrm{~N}$.

(2) The theoretical and experimental results are in good agreement with each other, which leads to an understanding that the mathematical model of the system is reasonable and can be applied to the design of more dexterous soft-handling grippers that will be developed in the near future.

(3) The PID control algorithm is sufficient for the stable grasping of a variety of objects with different. It was found the integral feedback gain plays a significant role in the control behaviour of the system. The optimal PID controller can be designed relatively easily by determining the feedback gains through the comparison of the system characteristic roots with the roots of the reference system and then adjusting the values referring to the simulated system response on the computer.

\section{REFERENCES}

[1] Z.W. Jiang, S. Chonan and J. Tani, "Tracking Control of a Miniature Flexible Arm using Piezoelectric Bimorph Cells", The International Journal of Robotics Research, Vol. 11, No. 3, pp. 260-267, 1992.

[2] S. Chonan, Z.W. Jiang and S. Sakuma, "Force Control of a Miniature Grigger Driven by Piezoceramic Bimorph Cells", Journal of Advanced Automation Technology, Vol. 6, No. 4, 247-254, 1994. 